\title{
ARE CONSTRUCTIVISM AND ENACTIVISM TWO OPPOSITE PHILOSOPHIES ON LEARNING MATHEMATICS?
}

\section{CONSTRUTIVISMO E ENATIVISMO SÃO DUAS FILOSOFIAS DE APRENDIZAGEM DE MATEMÁTICA OPOSTAS?}

\author{
Andrei Simionescu-Panait ${ }^{1}$
}

\begin{abstract}
Constructivism and enactivism are proposing opposite philosophies regarding the teaching of mathematics. The article explores the roots of kinaesthetic constructivism in Husserl's phenomenology of the lived body. Then, the article describes the main points on which enactivism explicitly differs from constructivism. Finally, the article lists the criteria for opposing or bringing together constructivism and enactivism and argues that constructivism and enactivism aim for different pedagogical results and have different teaching functions.
\end{abstract}

Keywords: Kinaesthetic constructivism; Enactivism; Husserl; I can; Learning.

Resumo: Construtivismo e enativismo são filosofias opostas com referência ao ensino da matememática. O artigo explora as raízes do construtivismo cinestésico na fenomenologia de Husserl sobre o corpovivente. A seguir, o artigo descreve os principais pontos em que o enativismo difere explicitamente do construtivismo. Finalmente, o artigo lista os critérios para opor ou reunir enativismo e construtivismo; e argumenta que ambos visam diferentes resultados pedagógicos e têm diferentes funcões de ensino.

Palavras-chave: Construtivismo cinestésico; Enativismo; Husserl; Eu posso; Aprendizagem.

\section{Introduction}

Usually, a philosopher's impact on subsequent philosophies and cultural behaviours becomes visible when his ideas are adopted and developed in various contexts. In the case of Husserl, his ideas have not only started the phenomenological movement, but have also crossed over into other areas of research, especially into the cognitive sciences. The educational field is no exception. In the last two decades, two directions in the theory of teaching mathematics have appeared in opposition to one another: constructivism and enactivism. Constructivism was originally designed by Piaget in the ' 60 s and is now being redesigned thanks to the kinaesthetic constructivism the Goldin-Meadow team proposes. The biggest critics constructivists have are the enactivists, like Davis, Proulx and Simmt. They adopt Varela's enactivism and criticise constructivists having a narrow view over the process of learning math that ignores the

\footnotetext{
1 Associated Professor at the Polytechnic University of Bucharest, Bucharest, Romania. E-mail: tesimionescu@gmail.com
} 
intersubjective aspect of classroom child-child and child-teacher interaction. Now, the interesting thing is that both kinaesthetic constructivism and enactivism have their conceptual roots in Husserlian phenomenology. The main question would then be: in what aspect are kinaesthetic constructivism and enactivism opposite of one another given that they are both inspired by phenomenology?

The article conceptualizes two criteria for opposing constructivism and enactivism and one criterion for being equivalent. First, the article presents the kinaesthetic constructivism and links it to phenomenological results from Husserl's Ideas II. Then, the article presents the main points of enactivist math education and links it to the phenomenological concept of intentionality. Third, the article argues that constructivism and enactivism aim for different pedagogical results and have different teaching functions.

\section{Kinaesthetic constructivism}

Phenomenology traditionally distinguishes between self and other (ZAHAVI, 2014). The gap between my experience and another person's experience cannot be directly crossed. I cannot experience the world through your body, through your subjective context, through your worldview. You, your worldview, my relation to you, my attempt to understand you, these are all objects of my consciousness. Empathy, as much as language, compensates for having this gap. Otherwise, the divide between myself and the other is infinite (LEVINAS, 1979). Constructivism relies on a consequence the phenomenological self-other divide provokes: people cannot directly transfer information between them. Instead, they have to construct ideas as part of their own consciousness. Consensus is therefore an indirect operation: each person constructs ideas in isolation and trusts that others mean the same thing when they share what they have constructed, that is, when they dialogue (VINTERE, 2018). When the math teacher talks about multiplying numbers with a child that has demonstrated the ability to perform basic arithmetic operations, they trust one another to talk about the same thing. However, such trust can often be problematic. Teachers can trust their students too much. Students often have unstable performances, they correctly solve one exercise and then incorrectly solve another similar exercise. They appear to have understood what to do and then misread the problem, ignore one step in solving the exercise or plainly become struck because of not knowing how to proceed. This builds up the constructivist agenda for math 
teaching: if every student constructs ideas in their subjective horizon, then how can teachers manage to indirectly control the way they construct their ideas?

Kinaesthetic constructivism is a type of constructivism that emphasizes the role of the teacher's movements and gestures in enhancing the quality of teaching. GoldinMeadow and her team champions the research on this method. The main idea is that teaching that is accompanied by gestures makes symbolic notions more intuitive. The learning child will then have a more substantial basis for understanding how addition or subtraction work when the teacher gradually eliminates apples and oranges and in turn introduces numbers into the process. A very telling example from Goldin-Meadow's research catalogue is Novack's (2014) article called “From Action to Abstraction: Using the Hands to Learn Math.” Its title indicates the main two opposite concepts at play: action and abstraction. Traditionally, one would think that children first learn to count three apples and then proceed to understand that the number " 3 " represents those three apples, or any other three objects. The problem with this view is that a child's performance can greatly vary when learning to perform operations with apple originating numbers. In the maths classroom, some children have a hard time understanding why three apples are suddenly a sign that has no material implications, while other children can instantly play the game of abstraction and pretend that " 3 " is the same as "apple apple apple." This situation points at the need to level up the understanding of as many children as possible. To do so, Novack and her team investigates the impact of action on teaching abstraction. The concreteness of apples takes a secondary role, as the teacher's movement steps in to take the limelight.

Action based teaching can be problematic on its own, because the child can easily pay attention to the object's irrelevant details and miss the conceptual content (MIX, 2010). For instance, a teacher has some purple magnetic numbers on the whiteboard. These magnetic numbers form a " $1+2+8=1+$ _" equation, through which the teacher teaches addition. The teacher gestures a gentle pick up of " 2 " and " 8 ", that she places in her palm. Then, she picks up the imaginary numbers from her palm and places them in the " " spot. Novack, Congdon, Hermani-Lopes and Goldin-Meadow (2014) call this a "concrete gesture," because the teacher's movement involves a connection to the material objects: the purple magnetic numbers. Even without the actual manipulation of magnetic numbers, the child's attention can be derailed. For instance, children are attracted to strong colors and expressive shapes, which makes some of them link the picking up of the purple 8 to the picking up of berries and further make them think about recess and 
candy. Or, some children would protest that the first two numbers are too "fat" to fit in the "_" space. Children easily divert their attention to the most interesting aspect for them, which on most occasions is not the conceptual aspect. Or, they use the concrete context to daydream about something else.

Issues that involve both concreteness and direct action on objects motivate Novack to research the effects of abstract gesturing when teaching addition. A teacher that uses abstract gesturing on the " $1+2+8=1+$ - will point at the " 2 " and the " 8 ", after which she will point at the "_.". It turns out that children that were taught addition through concrete gesturing were mostly proficient in solving trained problems, which rather require remembering, while children that were taught addition through abstract gesturing were mostly proficient in solving near and especially far transfer problems, that is, in problems that rather require abstraction and thinking than memorizing and imitating known solutions. Abstract gesturing, or pointing, is apparently the best way to teach using an example in order to stimulate the child to apply the example's inherent concept onto other examples.

The idea that movement is at the heart of abstraction is not new. Husserl's Ideas II (1989) is structured so that it showcases how experience is constituted bottom-up, where the "bottom" is the pre-reflective experience and the "up" is the reflective experience. The text's goal is to link the lived body to rationality. Paragraph 60 from Ideas II assesses the I move and the I can. Originally, the I move precedes the I can. The I move is a person's subjective consciousness of being in the midst of moving one's own body. This constitutes the I can, which is the consciousness of the ability to move, to do, to fulfill. The I can connects the power to do to the object at which the doing is directed (HUSSERL, 1989, p. 273). Yet, the I can does is not only involved in practical doings, but in the sphere of doxical positioning, that is, of opinions and judgment, which is related to imagination and memory. A centaur can exist. (HUSSERL, 1989, p. 274) I say "I could go outside". The I can that originates from movement transcends movement. Persons are conscious of the action they can perform without actually performing them. The I can is not necessarily an active part of consciousness: one can have the consciousness of being able to walk without thinking it or saying it.

From this Husserlian standpoint, the ability to perform addition, or other operations, is configured at the child's subjective level as an I can of the child's consciousness. As a consequence, the teacher does not only transfer a model to the child, a scheme to obtain the right answer. The teacher is also stimulating, in a purely 
constructivist fashion, an I can in the child's consciousness, namely that I can add up any numbers I would be presented with. From this standpoint, the link between gestures and abstraction is not surprising, since movement and gestures are foundational for abstracting and, unlike material concrete things that burden abstracting, movements have the same immateriality that abstractions have.

Kinaesthetic constructivism in teaching mathematics extends the Husserlian phenomenology of the lived body and movement into a practical domain. Yet not all phenomenological ideas are adopted into constructivism. The idea that each constructs his ideas points towards a more solipsistic version of phenomenology, one that misses the intersubjective dimension.

\section{Enactivism in teaching mathematics}

Husserl's phenomenology from his first two decades neglects the intersubjective dimension of experience. Or, at best, it remains bracketed until further development. The methodology of early phenomenology was in its inceptive stages and it was trying to clarify its fundamental noema-noesis distinction. Thus, a phenomenological project that takes the Logical Investigations or the Ideas volumes as its starting point will be a limited phenomenological project, as it will miss the intersubjective aspect of the transcendental self. In short, it will miss the idea that consciousness includes the "we consciousness", the consciousness that the subject is part of a community. This shapes the way we constitute objects, even in perception. For example, when learning to walk, a toddler will coordinate with the carer who supports the walking effort. The streets, houses, they are all constituted with the consciousness that someone else like me built them - they are not alien, not incomprehensible. Last example, we judge and perceive differently whenever someone produces an opinion about something or someone. All objects of consciousness are apprehended as intersubjective objects (HUSSERL, 1960). Yet, to develop a theory of teaching based on the intersubjective sphere implies a lesser focus on the efficiency in obtaining results in the classroom and a more intense focus on a freeform trial and error interaction between children on a given topic that will be less efficient but more open to the long term obtaining of a central skill: thinking. In this sense, Husserl's phenomenology that integrates intersubjectivity will spark a different type of theory on teaching mathematics than the earlier Husserlian phenomenology would. This intersubjectivity-oriented theory is now called enactivism in teaching. 
Enactivism in teaching has three main ideas (PROULX; SIMMT, 2013):

1. The child brings forth a world of significance with other people. This opposes the constructivist idea on interpretation. Constructivists hold the "pipelines" perspective: the world (the class) can have a limited number of possible interpretations. The child would fit his interpretation to those fixed possible interpretations that the class allows. Enactivism opposes this view by saying that there are no fixed possible interpretations the world class offers. Instead, the child will bring forth a world of significance and redo it depending on the problems that arise from his bringing forth. If there are no problems with the world of significance the child brought forth, he will repetitively bring forth the same version. The world the child brings forth is always negotiated with other people that bring forth different worlds of significance. An important concept here is Varela's coupling (VARELA; THOMPSON; ROSCH, 1991): the knower is coupled to the context, which includes other knowers.

2. The child brings forth the problems and the questions with other people. This opposes the constructivist idea on problems. Constructivists hold the "waiting" perspective: the world (the class) is full of problems that wait to be discovered by the knower (the child). The child would stumble upon the fixed problem and try to solve it as if there is a single and definitive answer waiting inside the problem for the child to disclose it. Enactivism opposes this view by saying that there are no fixed problems waiting for solvers to come and solve them. Instead, the child will bring forth the problem out of the context he also brings forth. These problems are formed as questions, who are not pre-existent, but are custom tailored by the child depending on the world of significance he enacts.

3. The child performs being knowledgeable with other people. This opposes the constructivist idea on knowledge. Constructivists hold the "warehouse" perspective: knowledge is to be gathered and repeated when necessary. Knowledge has the nature of quid, it is to be considered as a whatness. Knowledge is a something, a thing that is stored in the child's head. Enactivists oppose this idea and say that knowledge has the nature of quod, it is to be considered as a howness, not a thing but a process, a performance. The learning child does not have knowledge. Instead, the child is being knowledgeable. Teaching is not a process to make the child store "data" in his head, but a process to create and 
maintain habits of clear, organized and critical thinking, not to reproduce and imitate but to create and evaluate what he thinks.

Proulx and Simmt illustrate the three enactivist ideas through an example that involves two child and parent pairs. These two pairs are given the same mathematical problem: how many different arrangements that are two units wide can be created from, let us say, 7 dominoes ( $2 \times 1$ units) or less? One of the pair would go for a more geometrical approach, draw and count the possible arrangements, while the other pair would go for a more numerical approach in inventorying the possible arrangements. The intersubjective phenomenon of learning to think mathematically is then more aptly described through enactivist ideas than through constructivist ideas. Pair 1 brings forth the world of significance in terms of shapes that fill a given limited metrical surface on the paper. Thus the problem will not be fixed - how many arrangements are really there? - but it will be transformed by the world of significance that is brought forth by pair 1: how many shapes that are made out of dominoes can I draw so that they all have a width of two units? On the other hand, pair 2 brings forth a world of significance in terms of tables, numbers and signs that signal recurrences. Pair 2 will create a table with a column describing the number of dominoes that are used and a column describing how many combinations they found for that number of dominoes. From time to time, they would rethink and add a "+" to each number, signifying that the number has just increased. There could also be a third pair that would enact the world of significance and the problem in yet another way, as a probability problem, and they would have to bring forth formulas regarding permutations, arrangements and combinations. Yet, for the purpose of Proulx and Simmt's article, such formulas would be artificial and miss the point, which is that the interaction between mathematical thinkers defines the way they interpret the information, the problem and the way to transform the problem into an idea with at least an example, or so to say, into a solution.

The intersubjective presupposition lies at the heart of enactivism. This makes enactivism inspired teaching phenomenological mainly because enactivist minded teachers share with Husserlian phenomenologists the "back to the things themselves" motto. Two pairs that build their customized strategy from scratch to deal with a problem that they have just enacted strikingly illustrates this motto. Enactivists are interested in making the student explore the basics before transferring any ready-made formulas or models to them. Given this, the gap between constructivism and enactivism is radical.

\section{Are enactivism and constructivism opposed?}


One of the main tools phenomenology has is the epoché, which is translated as bracketing. Bracketing is very important in conceptual analysis and evaluation of a phenomenon because it allows the thinker to switch on and off between some aspects of the problem in order to see what transformation occurs in the analysed phenomenon when doing so. For instance, a child wins the school's 100 m race. The analysis about the child's subjectivity when running can first bracket intersubjectivity and look at the child's motivation without the crowd that is cheering or booing for him. Then, the analysis can switch on the intersubjective horizon and redo the conceptual analysis on, let's say, the child's motivation. The epoché is helpful because it allows for a clearer understanding of the function and limits of concepts.

The epoché can sometimes be used to bracket hidden presuppositions when evaluating a thinker's philosophy. This is done when the intention is creative. For example, a thinker evaluates another thinker's philosophy. Then, he shortcircuits an important presupposition from the thinker's philosophy. For example, this is what Husserl does in relation to Descartes' concept of doubt: Husserl shortcircuits the presupposition that there should be a way out of infinite doubting and that way is connected to the concept of God. This presupposition would eventually lead to the ontological argument in Descartes. In Husserl, on the other hand, such an argument would not make sense, because he shortcircuits Descartes' agenda and transforms doubting into the epoché, which, unlike in Descartes, does not need an external concept to give it finitude. So, after applying the epoché and shortcircuiting an important presupposition from the other thinker's philosophy, the thinker develops his own account, through eidetic variation (HUSSERL, 1973; REEDER, 2010) or some other procedure.

What enactivists do in relation to constructivists is no different. They bring forth the constructivist hidden agenda and relativize its importance by trying to explore the theory of teaching mathematics without it. Take Brent Davis' (1995) article on the reason for teaching mathematics. In that text, Davis argues that the importance of teaching mathematics is not for the socially accepted utility, like the fact that society needs engineers or that teaching mathematics is needed for the future teaching of even more mathematics (for instance, 3rd grade arithmetic is needed for middle school mathematics). Instead, mathematics is taught because it is an opportunity for the child to exercise abstract thinking together with other children of the same level. Davis thus underlines the philosophical character of teaching mathematics, namely that mathematics 
is not taught to make the child memorize formulas or have a chance at getting a job that is largely admired by society. Rather, mathematics is taught to classes of children in order to create small communities where abstract thinking with one another can be practiced. In such small classroom communities, the idea of having a mind that produces clear and distinct ideas, as Descartes would say, is rooted in the idea that such minds are produced by collaborating with others. The enactivist concept of coupling therefore creates a new, enactivist (and fairly philosophical) agenda for teaching mathematics. This enactivist agenda would promote collaborative thinking, which is opposite to the otherwise popular efficient thinking.

Is efficient thinking part of the constructivist agenda? Kinaesthetic constructivism, just like other recent versions of constructivism (concreteness fading), wants to be successful in making children solve near and far transfer problems. Usually, when a child has little to no difficulties with far transfer problems, it means that the child abstracts from what he knows and couples to a new situation. Therefore kinaesthetic constructivism is interested in making children be more efficient in relation to the problems they themselves bring forth in the classroom. In this sense, the philosophical and phenomenological input on kinaesthetics constructivism only regards the method of transferring the same recipes for thinking and not the content that is taught. Compare for instance the classroom where addition is taught through abstract gesturing to an enactivist classroom as described in Davis (1995). The enactivist classroom will not specifically ask "What are the missing numbers in $1+2+8=1+$ ?". Instead, it will ask "What can we say about 2/6?" It is easy to observe that the enactivist classroom is not preoccupied with the efficiency that drives the constructivist classroom, but with the trial and error community exploration of fundamental mathematics concepts. Such fundamental concepts are too fundamental to question and explore outside enactivist classroom. Therefore it is hard to say that kinaesthetic constructivism, even though inspired by the phenomenology of lived body and movement, goes back to the things themselves in terms of teaching mathematics. For now, the first opposition between kinaesthetic constructivism and enactivism is based on the criterion of having obvious results: efficient thinking vs. exploratory thinking.

The second opposition between enactivism and constructivism is between collaborative thinking and solipsistic thinking. Constructivism itself is built on the fundamental idea that each child constructs ideas in isolation, therefore it makes sense for the constructivism framework to propose an efficiency based teaching that targets each 
individual in the classroom. Enactivist teaching on the other hand does not target individuals in the classroom. Instead, it encourages the emergence of study groups in which individuals work together and end up behaving more as members of a group rather than individuals in a group. So on one hand, constructivist teaching overdrives some students into performance, at the cost of a collaborative attitude. On the other hand, enactivist teaching supports both fast and slow learners to investigate the otherwise indisputable principles, understand them, negotiate the understanding with same levelled children and appropriate them in further thinking efforts. The criterion represented by the desired student self-image polarizes collaborative thinking and solipsistic, or individualistic thinking.

This brings us to a common element that both enactivism and constructivism have: they both try to mitigate the discriminating effects on slow learners. Constructivism tries to make more children solve far transfer problem by using results from Husserlian phenomenology, cognitive sciences, or other epistemologies. After all, the kinaesthetic constructivist invention of abstract gestures aims to have more children in the classroom become proficient in arithmetic. And so does enactivism, even though they rely on having slow learners team up with fast learners so they couple in their thinking effort instead of relying on child friendly psychological tricks. The criterion of having an added value for the community reveals that both constructivism and enactivism want to facilitate the children's understanding of mathematics.

One thing should be noted. An exploratory endeavour will not only facilitate the learning of mathematics, but mainly the learning of a learning attitude. In this, constructivism and enactivism have different functions in the educational process. To explain the difference in function, one should distinguish between knowledge and thinking process. Constructivism wants to teach the child a handful of mathematical competencies without an appropriate underlying attitude, while enactivism wants to train the child into a thinking attitude that is customized to mathematics and can also be customized to other areas, like physics or philosophy. This mathematizing attitude includes a disposition to stay curious, an openness to rethink already established principles and to reformulate already solved problems, the patience to think without jumping to definitive solutions and the belief that the group's thinking effort is more important than getting recognized for delivering good answers. In this sense, constructivism is Cartesian in the fullest sense because it divides the learning subject (the child) from the learned object (mathematics). Enactivism, being phenomenological at its 
core, does not endorse this divide, so that the learned object is, in part, the attitude of the learning subject. Enactivism is rather interested in having the child work with himself when making an effort to mathematize with others. Under an enactivist optics, the child learns the skill to mathematize the world and himself. Constructivism and enactivism are therefore complementary because they aim to do different things: work on mathematical competencies and work on the mathematizing attitude. The aims of constructivism and enactivism can be formulated in Husserlian terms, as two distinct I cans. Mathematical competencies are read as an "I can compute", while the mathematizing attitude is read as "I can invent from scratch already established mathematical ideas for the sake of understanding their mathematical intention and purpose". Given such a distinction, an idea that arrives naturally is to have distinct classes that aim to train these two different I cans. The constructivist class represents the math class we have today, while the enactivist class represents a math class where the basic principles are collaboratively rethought and dead ends are explored for the sake of practicing thinking. Constructivism and enactivism would therefore not be competitive, but complementary philosophies of education that have different functions in the curriculum. Constructivism and enactivism would collaborate in developing future adults who can easily think mathematically.

\section{Bibliography}

DAVIS, B. Why Teach Mathematics? Mathematics Education and Enactivist Theory. For the Learning of Mathematics, Vancouver, v.15, n. 2, p. 2-9, june. 1995.

HUSSERL, E. Cartesian Meditations. The Hague: Martinus Nijhoff Publishers, 1960.

HUSSERL, E. Experience and Judgment. Evanston: Northwestern University Press, 1973.

HUSSERL, E. Ideas Pertaining to a Pure Phenomenology and a Phenomenological Philosophy, Second Book, Studies in the Phenomenology of Constitution. The Hague: Kluwer Academic Publishers, 1989.

LEVINAS, E. Totality and Infinity. The Hague: Kluwer Academic Publishers, 1979.

MIX, K.S. Spatial Tools for Mathematical Thought. In: MIX, K.S.; SMITH, L. B.; GASSER, M. (ed.). The Spatial Foundations of Language and Cognition. Oxford: OUP, 2010. p. 41-66.

NOVACK, M.A.; CONGDON, E.L.; HEMANI-LOPEZ, N. GOLDIN-MEADOW, S., From Action to Abstraction: Using Hands to Learn Math. Psychological Science, Washington, v. 25, n. 4, p. 903-910, apr. 2014.

PROULX, J.; SIMMT, E. Enactivism in mathematics education: moving toward a reconceptualization of learning and knowledge. Education Sciences \& Society, Macerata, v. 4, n. 1, p. 59-79, jan., 2013. 
REEDER, H. P. The Theory and Practice of Husserl's Phenomenology. Bucharest: Zeta Books, 2010.

VARELA, F.J.; THOMPSON, E.; ROSCH, E. The embodied mind: cognitive science and human experience. Cambridge: The MIT Press, 1991.

VINTERE, A. 2018 A Constructivist Approach to the Teaching of Mathematics to Boost Competencies Needed for Sustainable Development. Rural Sustainability Research, Jelgava, v. 39, n. 334, p. 2-7, aug. 2018.

ZAHAVI, D. Self and Other: Exploring Subjectivity, Empathy and Shame. Oxford: OUP, 2014.

Received in: August 03, 2020.

Accepted on: September 04, 2020. 